\title{
COMPARATIVE ANALYSIS OF MERCURY CONTENT IN HUMAN HAIR AND COSMETIC PRODUCTS USED IN DAR ES SALAAM, TANZANIA
}

\author{
CP Kinabo
}

Department of Geology, University of Dar es Salaam, P.O. Box 35052

Dar es Salaam, Tanzania.

kinabo_2003@yahoo.co.uk

\begin{abstract}
Total mercury (T-Hg) concentrations were analysed in human hairs and cosmetic products sold in Dar es Salaam Tanzania. The average total mercury ( $\mathrm{T}-\mathrm{Hg}$ ) concentrations in the scalp hair of females using mercury based cosmetic creams and soaps ranged from $7.0 \pm 0.4$ to $880 \pm 12 \mathrm{ppm}$. Highest T-Hg concentrations were found in females who work in beauty hair salons and the lowest concentrations were found among students. The average values in non-cosmetic users were found to be lower, with mercury ranging from $0.57 \pm 0.07$ to $8.29 \pm 1.22$ ppm. Analysis of cosmetic products indicated high values, ranging from $0.11 \pm 0.03$ to $8665 \pm 15$ ppm in soaps and $0.16 \pm 0.02$ to $25.30 \pm 4.2 \mathrm{ppm}$ in cosmetic creams. Mercury being a cumulative toxin, the findings suggests that women who use mercurial crèmes and soaps are likely to be poisoned as the compounds can enter the body through various pathways, including inhalation of vapor, ingestion, and skin contact.
\end{abstract}

\section{INTRODUCTION}

Skin lightening creams and soaps containing mercury manufactured in Europe is a multibillion-dollar industry, which is used for lightening skin, making the black skin light coloured. The products have colourful names, which associate royalty, romance and even religion with a white or pale skin, but many contain harmful chemicals like mercury and hydroquinone (BBC News, 2004). Following recent studies in Southern Africa (EGAJ 1996, Glahder et al 1999, Harada et al. 1999, Lindsey et al 1999, Lema 2002) experts concluded that women using such skin lightening products are thrilled with the results at first, but then red blotches appear, followed by dark blotches. Despite these effects and efforts by the Government of the United Republic of Tanzania to ban them in 1996 , by series of Acts (Pharmaceuticals \& Poisoning Act 1978, Tanzania Food, Drugs and Cosmetics Act 2003) more and more women in towns and cities are still using the products.

Following the WHO (1989, 1990 and 1991) the recommended values of mercury in cosmetics is less than $1 \mathrm{ppm}$ and in human hair less than 2 ppm. Values exceeding 10 ppm are a risk for pregnant women and children (US, EPA 2001, Agency for Toxic Substances and Disease Registry 1999, Harada et al. 2001, Lauwerys et al. 1978, WHO 1990, WHO 1991, Bonnie et. al. 1987). Analysis of different three imported soaps and two creams (Glahder et al 1999) bought in Tanzanian shops have indicated high mercury levels in soaps, with values of $6900 \mathrm{mg} / \mathrm{kg}$ equivalent to $6900 \mathrm{ppm}$ for Ricco - powerful germicidal soap; 6200 $\mathrm{mg} / \mathrm{kg}$ (or ppm) for Jaribu Gold Kwanza antiseptic soap; and $7000 \mathrm{mg} / \mathrm{kg}$ for Jambo $1^{\text {st }}$ choice soap have been reported. The values of creams were $<7 \mathrm{mg} / \mathrm{kg}$ for both Movate Super Clear complexion crème and Dear Heart Complete skin lightening treatment cream. Most of the cosmetic products are advertised as skin lightening products that are 'medicated' or 'antiseptic' offering false medicinal signatures (Lindsey et al. 1999).

Similar studies conducted by Earth Greener Activities Japan (1996) in the Lake Victoria 
Gold Field showed a high level of total mercury in hair up to $474 \mathrm{ppm}$ in non-miner women who have a habit of using beauty soaps containing a substantial amount of mercury.

Despite the efforts of Tanzania Food and Drugs Authority to ban number of toxic mercury bearing creams and soaps (Nipashe 2004), the number of women cosmetic users remains unchanged. Women users end up having legs pitted with tiny scars, uneven blotch skin due to skin-whitening creams (Villanacci 1996).

The study conducted in 2001 - 2003 in the city of Dar es Salaam, Tanzania consequently compares the total mercury content in cosmetic creams, soaps and their relationship to accumulation to human hairs.

\section{MATERIALS, METHODS AND EQUIPMENT}

Materials that were used in the study included replicate samples of 40 human hair taken from students, civil service servants and business people, distributed into 20 cosmetic users and 20 non-cosmetic users; 30 different brands of cosmetic soaps, and 30 different brands of cosmetic creams. All sampled people were interviewed following a standardized questionnaire that elicited information about their use of skin lightening creams and soaps, particular attention being paid to the nature of the cosmetics applied and the duration of their use. These samples were collected randomly from customers of local barbershops and hair salons in the District of Kinondoni, Dar es Salaam. Hair was chosen as a biological indicator because it contains 250 - 300 times more mercury than blood, which makes analysis for mercury easier (WHO, 1991). All hair samples were cut close to the scalp into pieces of about $1 \mathrm{~cm}$ in length.

Samples of cream and soap were purchased from different retail shops in Dar es Salaam based on items that were listed down by the sampled people in the questionnaires. All samples were stored according to type in polythene bags. Analysis of these samples was done at the Chief Government Chemist Laboratory in Dar es Salaam. The equipment used for total mercury determination was an Atomic Absorption Spectrophotometer, Unicam 939/959 model. The detection limit for the T-Hg was $0.001 \mathrm{ppm}$.

\section{RESULTS \\ Total Mercury (T-Hg) content in the scalp hair in Dar es Salaam}

According to the questionnaire information gathered, the practice of skin lightening was mainly common among females of all walks of life, with different ages and different social backgrounds. Hair samples obtained from 20 Tanzanian females using either skin lightening cosmetic creams or soaps showed that $85 \%$ were above 15 years and the rest were under 15 years old. In this study, all persons had been exposed to mercury through the use of different types of skin lightening creams and soaps containing substantial amount of mercury. The mean values ranged from $7 \pm 0.4$ to $880 \pm 12$ ppm. All subjects showed a high mean T$\mathrm{Hg}$ content in their hair exceeding the permissible levels of 2 ppm set by WHO.

Concentrations of mercury in hairs of students are shown in Table 1. They ranged from 7 to $68 \mathrm{ppm}$. The results of the concentrations of the metal in women working in offices and those doing various businesses are shown in Table 2 . The concentration seemed to increase with age and ranged from $92 \mathrm{ppm}$ for a 27 year office woman to $880 \mathrm{ppm}$ for a 31 year office woman.

Other groups, indicated that nurses are among the least affected group, followed by hotel attendants. Remarkably, hair saloon attendants have high-elevated levels of mercury - a case of 18 year young woman which showed a $\mathrm{Hg}$ - concentration levels of more than 300 ppm. 
Table 1: $\quad \mathrm{T}-\mathrm{Hg}$ concentration in students' hairs

\begin{tabular}{lcccc}
\hline Occupation & Age Years & $\begin{array}{c}\text { Duration of use } \\
\text { (years) }\end{array}$ & $\begin{array}{c}\text { Usage frequency } \\
\text { per day }\end{array}$ & $\begin{array}{c}\text { Average T-Hg (ppm) } \pm \\
\text { SDE*** }\end{array}$ \\
\hline Students & 13 & 1 & 2 & $7.0 \pm 0.4$ \\
& 14 & 2 & 1 & $23.0 \pm 0.2$ \\
& 15 & 3 & 2 & $44.0 \pm 0.5$ \\
& 20 & 4 & 2 & $50.0 \pm 0.5$ \\
& 23 & 4 & 2 & $68.2 \pm 0.5$ \\
\hline
\end{tabular}

$\left(\mathrm{SDE}=\right.$ Standard Error; d.1. = detection limit of $0.001 \mathrm{ppm} ;{ }^{* *}$ Mean was calculated from three replicates of each sample.)

Table 2: $\quad$ T-Hg concentration in hair among women cosmetic users

\begin{tabular}{lcccc}
\hline \multicolumn{1}{c}{ Occupation } & $\begin{array}{c}\text { Age } \\
\text { Years }\end{array}$ & $\begin{array}{c}\text { Duration of use } \\
\text { (years) }\end{array}$ & $\begin{array}{c}\text { Application per } \\
\text { day }\end{array}$ & $\begin{array}{c}\text { Average T-Hg (ppm) } \pm \\
\text { SDE** }\end{array}$ \\
\hline Office workers & 27 & 3 & 2 & $92.0 \pm 1.0$ \\
& 28 & 5 & 2 & $132.0 \pm 3.5$ \\
& 29 & 6 & 2 & $387.0 \pm 6.0$ \\
& 29 & 7 & 2 & $530.0 \pm 10$ \\
Business & 31 & 2 & 3 & $880.0 \pm 12$ \\
women & 29 & 5 & 2 & $110.3 \pm 1.7$ \\
& 30 & 6 & 2 & $255.0 \pm 5.1$ \\
Nurses & 33 & 6 & 2 & $473.8 \pm 6.2$ \\
& 29 & 2 & 2 & $490.0 \pm 8.0$ \\
Hotel & 28 & 5 & 2 & $55.8 \pm 0.4$ \\
attendants & 27 & 3 & 1 & $77.3 \pm 0.8$ \\
& 23 & 1 & 2 & $196.0 \pm 2.4$ \\
Hair saloon & 18 & 1 & 2 & $350.0 \pm 4.5$ \\
workers & 26 & 4 & 2 & $360.0 \pm 8.5$ \\
\hline
\end{tabular}

$(\mathrm{SDE}=$ Standard Error; d.1. $=$ detection limit of $0.001 \mathrm{ppm} ; * *$ Mean was calculated from three replicates of each sample).

In general the results showed that $\mathrm{T}-\mathrm{Hg}$ levels in hair samples differed markedly among females with different occupations, as presented in Figure 1.

Average $\mathrm{T}-\mathrm{Hg}$ levels were lowest in students (average age of 17) where subjects had average $\mathrm{T}-\mathrm{Hg}$ concentration of $38.4 \mathrm{ppm}$. Nurses (average age of 28.5) had average T$\mathrm{Hg}$ concentration of $66.6 \mathrm{ppm}$, which was approximately 1.7 times the level in student subjects. Hotel attendants (average age of 25) had average $\mathrm{T}-\mathrm{Hg}$ concentration of 273 ppm, which was 7.1 times the average in students. Businesswomen (average age of 30.2) had average T-Hg concentration of 332 ppm, which was approximately 8.6 times the level in students. Office workers (average age of 28.8) had average T-Hg level of 404 ppm, which was approximately 10.5 times 
the level in students. Average $\mathrm{T}-\mathrm{Hg}$ was highest in females working in hair saloons (average age of 22) where subjects had average $\mathrm{T}-\mathrm{Hg}$ concentration of $460 \mathrm{ppm}$, which was 12 times the level in students.
Usage of skin lightening cosmetics depends on the nature of the job, for example females who work in hair saloons are more influenced to use cosmetics due to their availability in their working places.

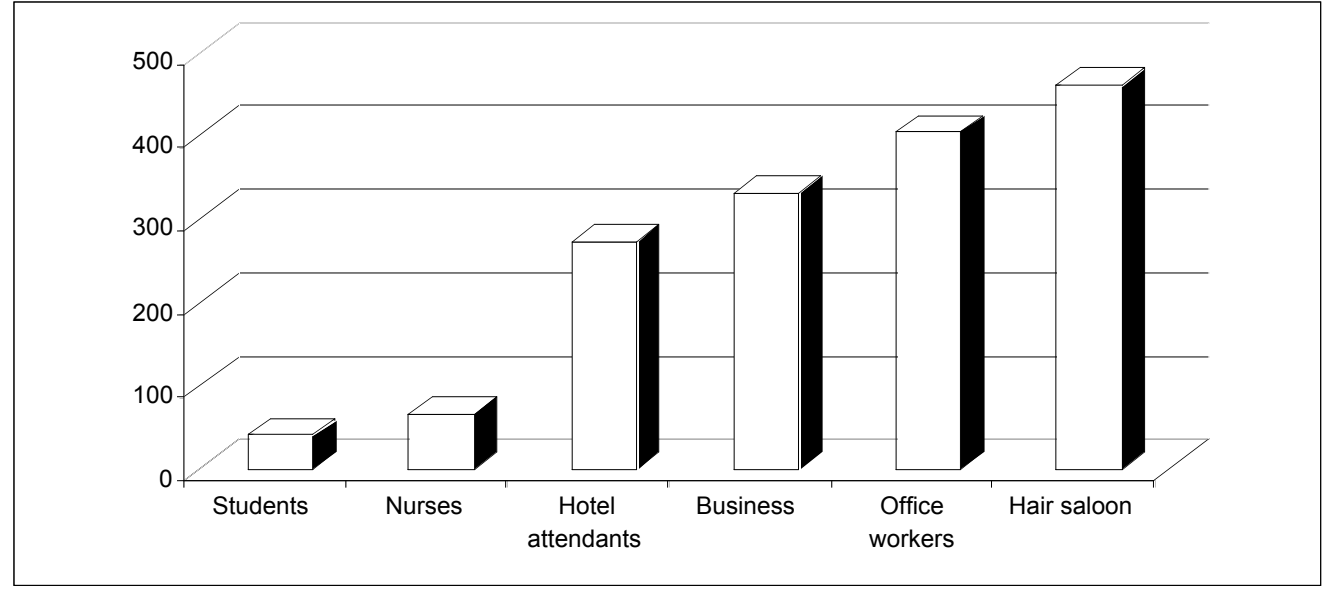

Figure 1: Distribution of T-Hg in ppm, in hair, among women of different occupations

Table 3: Distribution of $\mathrm{T}-\mathrm{Hg}$ in $\mathrm{ppm}$, in hair, among non-cosmetic users of different occupations

\begin{tabular}{cccc}
\hline Occupation & Age & Sex & $\begin{array}{c}\text { Average T-Hg } \\
(\mathbf{p p m}) \pm \text { SDE** }\end{array}$ \\
\hline \multirow{6}{*}{ Students } & 18 & $\mathrm{M}$ & $0.78 \pm 0.06$ \\
& 22 & $\mathrm{M}$ & $0.96 \pm 0.04$ \\
& 24 & $\mathrm{M}$ & $1.43 \pm 0.07$ \\
& 17 & $\mathrm{M}$ & $1.46 \pm 0.22$ \\
& 19 & $\mathrm{M}$ & $1.62 \pm 0.21$ \\
& 20 & $\mathrm{~F}$ & $1.75 \pm 0.21$ \\
& 24 & $\mathrm{M}$ & $1.83 \pm 0.31$ \\
& 17 & $\mathrm{~F}$ & $2.50 \pm 0.15$ \\
& 16 & $\mathrm{~F}$ & $2.75 \pm 0.13$ \\
\hline
\end{tabular}

Mercury concentration from non-cosmetic users is generally low. The mean $\mathrm{T}-\mathrm{Hg}$ concentrations (ppm) in the hair of noncosmetic users, of both males and females, ranged from $0.57 \pm 0.07$ to $8.29 \pm 1.22$

\begin{tabular}{lccc}
\hline \multicolumn{1}{c}{ Occupation } & Age & Sex & $\begin{array}{c}\text { Average T-Hg } \\
(\mathbf{p p m}) \pm \text { SDE** }\end{array}$ \\
\hline Student & 16 & $\mathrm{~F}$ & $3.13 \pm 0.42$ \\
Barber & 27 & $\mathrm{M}$ & $0.57 \pm 0.07$ \\
& 26 & $\mathrm{M}$ & $0.61 \pm 0.03$ \\
Teacher & 33 & $\mathrm{M}$ & $1.20 \pm 0.08$ \\
Office worker & 32 & $\mathrm{M}$ & $1.73 \pm 0.13$ \\
Business & 27 & $\mathrm{M}$ & $1.80 \pm 0.14$ \\
& 27 & $\mathrm{M}$ & $1.80 \pm 0.26$ \\
House girl & 18 & $\mathrm{~F}$ & $2.34 \pm 0.17$ \\
& 19 & $\mathrm{~F}$ & $3.04 \pm 0.11$ \\
House & 27 & $\mathrm{~F}$ & $8.29 \pm 1.22$ \\
wife/Sales & & &
\end{tabular}

(Table 3). The results show that females had more $\mathrm{T}-\mathrm{Hg}$ concentration in their hair as compared to the males. For instance, the average mercury levels were high in female workers with a mean $\mathrm{T}-\mathrm{Hg}$ concentration of 
$4.56 \mathrm{ppm}$ and low in male workers with a mean $\mathrm{T}-\mathrm{Hg}$ level of $1.29 \mathrm{ppm}$. Among the students, the average $\mathrm{T}-\mathrm{Hg}$ concentration in hair was higher in females than in the male subjects with a mean $\mathrm{T}-\mathrm{Hg}$ level of 2.53 ppm and 1.43 ppm respectively. The high $\mathrm{T}-\mathrm{Hg}$ level in female subjects could be attributed to the fact that females use other types of cosmetics other than creams and soaps, which may contain mercury.

Some mercury was found in normal individuals not known to have been exposed to the metal. The source of mercury could be due to natural mercury emanations, which can easily enter human body through food chain and accumulated in hair and other organs.

\section{T-Hg in soap samples}

Among the samples of soap analysed, about $20 \%$ of the samples, namely Clear Essence from USA, Ikb, Mililo, Skin Success and Ultra both from UK and Protex from Kenya, were free from mercury. One soap sample, Shabba, which did not, indicated the manufacturer or country of origin had mercury content of $0.11 \pm 0.03 \mathrm{ppm}$. The rest, showed a very high $\mathrm{T}-\mathrm{Hg}$ content exceeding the maximum WHO permissible limit of $1 \mathrm{ppm}$, which can be divided into three groups. The first group contains mercury levels below 100 ppm, which included Niuma (Spain) $2.32 \pm 0.60 \mathrm{ppm}$; Dove soap (Lever Brothers SA) $2.70 \pm 0.12$ ppm; Murphy's Oil Soap (no indication of country of origin) $12.0 \pm 2.8 \mathrm{ppm}$; Soft Scrub (no indication of country of origin) $13.0 \pm 2.3$ ppm; Top lemon plus (no indication of country of origin) $17.04 \pm 4.9$ ppm; Princes (Princess products Ltd) $30.8 \pm$ 5.4 ppm; Rico lemon fresh (Rico Skin care Ltd.) $87.5 \pm 2.5 \mathrm{ppm}$ and Sukisa Bango (Check park Ltd. UK) $99.9 \pm 8.0$ ppm.

The second major category consists of soap products with $\mathrm{Hg}$ - content varying from 100 to $1000 \mathrm{ppm}$. These were Jambo Binti (Jambo products) $109.4 \pm 8.5$; Pimplex (Kenya) $127.4 \pm 3.7$ ppm; Top (Spain)
$171.9 \pm 8.1$; Miki (C \& C International, UK) $255.2 \pm 5.2 \mathrm{ppm}$; Rico medicated (Skin care Ltd. UK) $270.0 \pm 5.8 \mathrm{ppm}$ and Crusader Safety (UK) $271.9 \pm 6.8$ ppm.

The last category consists of soap samples with mercury levels above 1000 ppm, which included Amira green (England) $1107 \pm 13$ ppm; Asepso (Not indicated) $2060 \pm 15$ ppm; Derma Scrub (Not indicated) $5000 \pm$ 10 ppm; Jaribu Kwanza (UK) $5310 \pm 30$ ppm; Mekako (Americ Enterp. Ltd. Dubai) $5700 \pm 10$ ppm; Amira Blue (UK) $5880 \pm$ 20 ppm; Tura Medicated (Tura International Ltd. UK) $6560 \pm 10$ ppm; Dear heart (USA) $8100 \pm 30 \mathrm{ppm}$ and Movate Esapharma, (Italy) $8665 \pm 15$ ppm.

\section{T-Hg in cosmetic creams}

All the cream samples collected did not show any declaration on the packaging that they contain mercury or mercury complexes. Nonetheless on analysis only $36.6 \%$ showed to contain no detectable mercury content, which was in agreement with the specification on the packaging. These were Clearessence (USA), Crusader (EIL, Ltd. UK), Dark \& Lovely (Hargell, INC. Italy), Dear Heart (Cosmetic expression Ltd. USA), Ikb (Ikb Industries Ltd), Niuma (Spain), Skin Success (England), Paris cream (No indication of country of origin), Princess (Princess Products Ltd. Spain), Rose Cream (No indication of country of origin) and Top (UK). Samples with traces of $\mathrm{T}-\mathrm{Hg}$ which was within the WHO maximum permissible level of $1 \mathrm{ppm}$ included Miki (C\&C International Ltd. UK) $0.16 \pm 0.02 \mathrm{ppm}$; Kelly (Kelly Int. cosmetics, Indonesia) 0.43 \pm 0.03 ppm; Ultra (UK) $0.43 \pm 0.02$ ppm; Fair \& Lovely (India) $0.54 \pm 0.10 \mathrm{ppm}$ and Fade cream (Indonesia) $0.60 \pm 0.07 \mathrm{ppm}$. Mecurial crèmes with $\mathrm{T}-\mathrm{Hg}$ less than 100 ppm included Ideal Cream (Bechara Ltd. Lebanon) $1.18 \pm 0.11 \mathrm{ppm}$; Movate (Italy) $1.50 \pm 0.09$ ppm; Mekako (Nish Cosmetics Ltd. UK) $1.59 \pm 0.03$ ppm; Melanax (Pakistan) $1.73 \pm 0.03$ ppm; Rico (Rico Skin Care Ltd. Spain) $1.90 \pm 0.16$ ppm; Jambo Binti (Jambo Products) $2.33 \pm 0.07$ 
ppm; Jaribu Kwanza (Nish Cosmetics Ltd. UK) $5.04 \pm 1.52 \mathrm{ppm}$; Butone (Swiza Laboratories, Zambia) $14.0 \pm 2.8 \mathrm{ppm}$; Jaribu B (UK) 17.91 $0.21 \mathrm{ppm}$; Yesako (Nish Cosmetics, England) $19.95 \pm 1.15$ ppm; Mercury (Ronmead Ltd. England) $20.15 \pm 1.50 \mathrm{ppm}$; Movate Gel (Milan, Italy) $20.17 \pm 0.10 \mathrm{ppm}$ and Amira (Nish Cosmetics Ltd. UK) $25.30 \pm 4.2 \mathrm{ppm}$. One cream sample had T-Hg content of $5650 \pm$ $10 \mathrm{ppm}$ that was considered to be extreme. This was not compiled with the other results. This cream's concentration of T-Hg matched those of skin lightening soaps.

\section{DISCUSSIONS}

Traces of mercury were found in individuals not known to be exposed to the metal, which accounts for natural mercury in environment, which can easily enter the food web and bio-accumulate in human hair. T$\mathrm{Hg}$ concentrations in cosmetic creams were low, as compared to the $\mathrm{T}-\mathrm{Hg}$ concentration range found in cosmetic soaps. The results agree well with those of Glahder et al. (1999) of which there were no mercury found in cosmetics but in soaps.

On average, the mean $\mathrm{T}-\mathrm{Hg}$ concentrations in the 13 non-cosmetic male users ranged from $0.57 \pm 0.07$ to $1.9 \pm 0.2 \mathrm{ppm}$ while the mean T-Hg concentrations in the 7 noncosmetic female users were higher, ranging from $1.75 \pm 0.21$ to $3.13 \mathrm{ppm}$.

Ohno et al. (1984) and Harada et al. (1999) found that the average upper limit of $\mathrm{T}-\mathrm{Hg}$ level in normal hair is $10 \mathrm{ppm}$. The same results were also observed during in this study, which were below $10 \mathrm{ppm} \mathrm{T}-\mathrm{Hg}$ concentration in the hair samples for noncosmetic users in the City of Dar es Salaam.

The low values of mercury concentration found in mercury non-users are due to natural mercury found in the environment. In addition, eminent mercury concentration found in non-users can also be originated from the remainder of mercury in soaps, which goes with the wastewater into the environment and back to human beings.

The results on contents of T-Hg in women hair that use mercurial crèmes and soaps are particularly high and sufficient to cause adverse health effects to humans. A concentration of $50 \mathrm{ppm}$ of T-Hg in human hair is a lower critical level of minamata disease (Harada et al. 1999), which was observed in all women using creams containing mercury in the city of Dar es Salaam, Tanzania. All hair samples collected during the study contained different amounts of mercury within the concentration range of 0.11 to $8665 \pm 10 \mathrm{ppm}$. Most of these T-Hg concentrations are much higher than the maximum permissible level for Tanzania and WHO norms, $2 \mathrm{ppm}$. UN reported that a woman who used cosmetic soap containing mercury had up to 400 times more mercury in the blood than non-users of such soaps (WHO 1991). Similar results found in this study agrees quite well as cosmetic users have more than 100 times more mercury in hairs than non users.

While the country has health policies and laws on management of chemicals e.g. Pharmaceuticals and Poisons Act, 1978 (Act No.9 of 1978); The Mining Act, 1998; Drugs and Prevention of illicit Drugs Act, 1995 (Act No. 9 of 1995); The Standards Act, 1975 (Act No. 3 of 1975); National Environment Management Act, 1983, (No. 18 of 1983); Tanzania Food, Drugs and Cosmetics Act No. 1 of 2003, most of them are not effectively enforced. In driving to educate the users on harmful chemicals recently the Ministry of Health, United Republic of Tanzania have issued a list of banned local and imported cosmetic products through the local media (Nipashe 2004). However, much remains to be done by the newly established Tanzania Food and Drugs Authority (TFDA), which in 2003 successfully pushed for legislation to prosecute businesses, which sell the banned cosmetic products from the unregulated multi million-dollar cosmetic industry. 


\section{ACKNOWLEDGEMENTS}

I am indebted to the Faculty of Science, University of Dar es Salaam for financial assistance through the SIDA SAREC Core Support funding, Ms. Emmy Lema and supporting staff of Chief Government Chemist Laboratory in Dar es Salaam for the laboratory technical work.

\section{REFERENCES}

Agency for Toxic Substances and Disease Registry (ATSDR). 1999. Managing Hazardous Materials Incidents. Volume III - Medical Management Guidelines for Acute Chemical Exposures.

BBC News, Tanzania Counts Cost Of 'white Skin' 23 November 2004.

Bonnie R, Evrard C, Gennart P and Bernard A 1987 Prenatal and early postnatal intoxication by inorganic mercury resulting from the maternal use of mercury-containing soap. J. Hum. Toxicol. 6: $253-256$.

Drugs and Prevention of illicit Drugs Act 1995 (Act No. 9 of 1995) United Republic of Tanzania. Ministry of Health.

Earth Greener Activities Japan 1996 Final Report of the case study of the state of mercury pollution (contamination) in Lake Victoria Basin. The Japanese NGO mission for Lake Victoria environmental monitor. $8 \mathrm{p}$.

Glahder CM and Appell PWU 1999 Mercury in soap in Tanzania. NERI Technical Report No.306. Department of Arctic Environment Geological Survey of Denmark and Greenland, Department of Economic Geology. 19 p.

Harada M, Nakachi S, Cheu T, Hamada H, Oho Y, Tsuda T, Yanagida K, Kizaki T and Ohno H 1999 Monitoring of mercury pollution in Tanzania; relation between head hair mercury and health. Sci. Total Environ. 227: 249 - 56.

Harada M, Nakachi S, Tasaka K, Sakashita S, Muta K, Yanagida K, Doi R, Kizaki T, Ohno H 2001 Wide use of skinlightening soap may cause mercury poisoning in Kenya. Sci. Total Environ. 269 (1-3): $183-7$.

Lauwerys R, Bonie C, Evrard P, Gennart J and Bernard A 1978 Prenatal and early postnatal intoxication by inorganic mercury resulting from the maternal use of mercury-containing soap J.Hum. Toxicol 6: 253 - 256

Lema ES 2002 A comparative analysis of T$\mathrm{Hg}$ content in cosmetic creams and soaps and in human hair in Dar es Salaam. Master of Science Dissertation, University of Dar es Salaam.

Lindsey K, Balagizi I, Mbuta K, Hirt H 1999 Report on "Mercury soaps: A modern day scandal". Action for Natural Medicines (Anamed) publications. $16 \mathrm{p}$.

Mining Act 1998 United Republic of Tanzania, Ministry of Energy and Minerals.

National Environment (Management) Act 1983 (No. 18 of 1983) United Republic of Tanzania.

Nipashe Newspaper, Dar es Salaam, Tanzania August 4, 2004

Ohno H, Doi R, Tani Y and Harada M 1984 Mercury content of scalp hair from residents on the coast of Jakarta Bay. Bull. Environ. Contamin. Toxicol. 382 385.

Pharmaceuticals and Poisons Act 1978 United Republic of Tanzania, Ministry of Health, (Act No.9 of 1978).

Standards Act 1975 (Act No. 3 of 1975) United Republic of Tanzania. Ministry of Health.

Tanzania Food, Drugs and Cosmetics Act No. 1 of 2003, United Republic of Tanzania, Ministry of Health.

US EPA 2001 Blood and Hair Mercury Levels in Young Children and Women of Childbearing Age-United States, $M M W R$, 50: 140 - 143.

Villanacci J F 1996 Mercury poisoning associated with beauty cream in Texas, New Mexico, and California. Med. J., 45: 400 - 403.

WHO 1989 Mercury-Environmental Aspects Environmental Health Criteria 86, World Health Organization, Geneva 115 . 
Kinabo - Comparative analysis of mercury content in human hair ...

WHO 1990 Methylmercury Environmental Health Criteria 101, World Health Organization, Geneva. 144 p.
WHO 1991 Inorganic Mercury Environmental Health Criteria 118. World Health Organization, Geneva, $159 \mathrm{p}$. 